\title{
Reassessment of the Structural Composition of the Alkenone Distributions in Natural Environments Using an Improved Method for Double Bond Location Based on GC-MS Analysis of Cyclopropylimines
}

\author{
Jordi F. López and Joan O. Grimalt \\ Department of Environmental Chemistry, Institute of Chemical and Environmental Research (IIQAB-CSIC), \\ Barcelona, Catalonia, Spain
}

\begin{abstract}
The usefulness of n-propyl-, iso-propyl-, and cyclopropylamines for the location of double bonds positions in $\mathrm{C}_{37}-\mathrm{C}_{40}$ alkenones after formation of imino derivatives has been evaluated. Cyclopropylamine is the best reagent for its high reaction yields, GC retention time difference between derivatives and precursor compounds, and absence of generation of byproducts. The use of this $\mathrm{C}_{3}$ amine involves higher sensitivity and ease of application than previously reported $\mathrm{C}_{5}$ amines. Examination of a large group of alkenones from cultures of Emiliania huxleyi, water particles, and recent and ancient sediments with cyclopropylamine derivatization shows that, in all cases, the double bonds were located at the same carbon atom distance from the carbonyl group, and spaced in intervals of five methylene groups either from the carbonyl or between them, e.g., at sites $7,14,21$, and 28 . This result represents a correction from previous assumptions in which double-bond positions were situated by reference to the methyl end. 4,4-Dimethyloxazoline derivatization of hexatriacontenoates showed that these compounds have also their unsaturations with seven carbon atom spacing and counting by reference to the carboxyl group. The concurrence of both series of isomers in compounds of different oxygen functionalities indicates that the precursor haptophycean algal species have a major biosynthetic pathway leading to the formation of these lipids. The data presented in this work unify the structures of the known alkenones in the present and the recent past under a common metabolic pathway. (J Am Soc Mass Spectrom 2006, 17, 710-720) @ 2006 American Society for Mass Spectrometry
\end{abstract}

I

n a previous manuscript, a method for double-bond location in $\mathrm{C}_{35}-\mathrm{C}_{41}$ alkenones was proposed [1]. These compounds currently encompass mixtures of straight chain methyl and ethyl ketones with one to four unsaturations and all trans-configuration. They constitute one of the groups of marine lipids most intensively studied because of the clear relationship between composition of the $\mathrm{C}_{37}$ di- and triunsaturated homologues and sea surface temperature (SST) $[2,3]$ being widely used for the estimation of past ocean temperatures [4-7].

Structural characterization of these low volatile compounds is needed for a full understanding of their biosynthetic origin and geochemical meaning. However, attempts to locate the positions of the double bonds based on GC-MS studies of vicinal bistrimethylsilyl ethers [8] or dimethanethiols [9] had limited suc-

Published online March 15, 2006

Address reprint requests to Dr. J. O. Grimalt, Department of Environmental Chemistry, Institute of Chemical and Environmental Research (IIQABCSIC), Jordi Girona 18-26, 08034-Barcelona, Catalonia, Spain. E-mail: jgoqam@cid.csic.es cess because they generated derivatives with much longer retention times than the original compounds [10]. Recently, the application of a novel technique based on the mass spectra of phenyl and cyclopentylimines has been used to characterize distributions of alkenones found in hypersaline sediments and coastal tidal ponds [1].

However, the study of alkenone structures in samples from old sediments, e.g., those covering the last $250 \mathrm{k}$ years of the history of the Mediterranean SST [6], showed that in some cases the sensitivity of the methods available [1] was not sufficient for the unambiguous determination of the position of the unsaturations because of the low concentrations of these compounds. Keeping in mind the previous experience with the use of $\mathrm{C}_{5}$ amines, smaller molecular weight homologues with a lower boiling point were tested. n-Propyl-, isopropyl-, and cyclopropylamine were chosen for their availability and relative low cost. The usefulness of these three $\mathrm{C}_{3}$ isomeric amines has been assayed, both on synthetic standards and on environmental samples. Their study has provided a new method involving 
significant improvements in both preparation ease and sensitivity compared with the amino derivatives previously described [1]. The application of the technique to algal cultures, marine sediments, and particulate matter has allowed characterizing the double-bond positions in all the alkenones known to occur in environmental samples.

\section{Experimental}

\section{Materials and Reagents}

Analysis grade solvents, dichloromethane (DCM), methanol $(\mathrm{MeOH})$, hexane, isooctane, ethyl acetate, and toluene, $\mathrm{N}, \mathrm{O}$-bis-trimethylsilyl-trifluoroacetamide (BSTFA), molecular sieves (4 A), potassium hydroxide $(\mathrm{KOH})$, silica gel 40 (70-230 mesh), aluminum oxide 90 (neutral, 70-230 mesh), and sodium sulfate were purchased from Merck (Darmstadt, Germany). Tetrahydrofurane (THF), aniline (99.5\%), cyclopentylamine (99\%), cyclopropylamine $(99 \%)$, propylamine $(99 \%)$, isopropylamine $(99 \%)$, sodium p-toluenesulfinate hydrate, 2-amino-2-methylpropanol (AMP), N-methyl-Nnitroso-p-toluenesulfonamide (Diazald), and 1,4-dioxane $(99+\%$, ACS reagent) were from Aldrich (Milwaukee, MI). The synthetic standards (E,E,E)-8,15,22-heptatriacontatrien-2-one and (E,E)-15,22-heptatriacontadien2-one were generously provided by Professor J. R. Maxwell, University of Bristol, UK [11].

The $4 \AA$ molecular sieves were heated overnight at $500{ }^{\circ} \mathrm{C}$, and re-activated by heating at $150{ }^{\circ} \mathrm{C}$ for $1 \mathrm{~h}$ before use. Anhydrous sodium sulfate was heated overnight at $350{ }^{\circ} \mathrm{C}$ before use. Aliquots of toluene and THF were stored overnight in activated molecular sieve before use. Either flat bottom or conical $2 \mathrm{~mL}$ vials were used for reaction and GC-MS analysis. These vials were screw-capped with Teflon-lined white silicone-rubber septa. The septa had been routinely washed by soaking in DCM and repeatedly changing the solvent until foaming was reduced to a minimum to eliminate silicone peaks that irreversibly interfere with both alkenones and imines.

\section{Sampling}

Several samples were obtained from hypersaline coastal areas of the Iberian Peninsula [12], southeastern France [13], and Orkney Islands [14]. They were also obtained from several Emiliania huxleyi strains and water column particles from Skagerrak and Midatlantic sites [15]. Deep sea sediments from the Alboran Sea were also included in the study [6].

\section{Extraction and Fractionation}

Detailed descriptions of the analytical procedures for extraction and isolation of the alkenone mixtures are given in the publications cited above. Samples were extracted with a mixture of $\mathrm{DCM} / \mathrm{MeOH}(2: 1)$, either by sonication or Soxhlet reflux. The extracts were hydrolyzed overnight at room temperature in solutions of $6-10 \% \mathrm{wt} / \mathrm{vol} \mathrm{KOH}$ in $\mathrm{MeOH}$. Extraction with hexane yielded a fraction enriched in neutral compounds which, in samples with low alkenone content, e.g., ancient Alboran Sea sediments, was not fractionated further. In the other cases, fractionation was carried out on chromatographic columns filled with $5 \%$ water deactivated aluminum oxide (top) and silica gel (bottom) by elution with solvent mixtures defining a polarity gradient [hexane $(20 \mathrm{~mL})$, hexane:DCM (90:10, $20 \mathrm{~mL}$; 80:20, $40 \mathrm{~mL}$; 25:75, $20 \mathrm{~mL}$ ), DCM:MeOH (90:10, $40 \mathrm{~mL})]$. The ketone-enriched fraction was eluted with hexane/DCM $(25: 75,20 \mathrm{~mL})$. This fraction was dried under nitrogen, dissolved in isooctane, and stored at $-20^{\circ} \mathrm{C}$. The neutral fractions were derivatized with BSTFA.

\section{Preparation of Alkenone Derivatives}

The basic description of the derivatization procedure for imino derivatives of the ketones can be found in [1]. Now, an improved method based on the use of smaller molecular weight and lower boiling point amines is described. The reactions were held in $2 \mathrm{~mL}$ vials screwcapped with a Teflon lined silicone septum. The derivatives were prepared from previously evaporated standards or samples by addition of $50 \mu \mathrm{L}$ of the corresponding amine and $250 \mu \mathrm{L}$ of THF. The solution was dried by the addition of either 10-15 beads of molecular sieves or a layer of 2-3 $\mathrm{mm}$ anhydrous sodium sulfate. Air was purged with argon before vial capping, and the vials were kept in an oven at $80^{\circ} \mathrm{C}$ for $2 \mathrm{~h}$. The vials were then cooled to room temperature and stored at $-20^{\circ} \mathrm{C}$. Before GC-MS analysis, aliquots of the reaction crude were evaporated to dryness under a gentle nitrogen stream and dissolved in toluene.

\section{4,4-Dimethyloxazoline Derivatives}

Diazomethane was prepared from Diazald by distillation as indicated in the Aldrich Company Technical Bulletin AL-180. The methylated acid fractions or the ester-ketone fractions containing the alkyl alkenoates were evaporated to dryness under nitrogen in $2 \mathrm{~mL}$ screw-cap vials. An excess of 2-amino-2-propanol (250 $\mu \mathrm{L})$ was added and the vials were flushed a few seconds with nitrogen or argon and covered with a temperature resistant cap and Teflon-lined silicone rubber septum. The vials were heated at $210^{\circ} \mathrm{C}$ for $2 \mathrm{~h}$ according to a recent modification [16] of a standard 4,4-dimethyl-oxazoline preparation method [17] for long-chain fatty acids. The reaction crude was cooled at room temperature, dissolved in $1 \mathrm{~mL}$ of DCM, and transferred to a test tube containing $2 \mathrm{~mL}$ of distilled water. After vortex stirring, the top water layer was removed, $2 \mathrm{~mL}$ of distilled water was added, and the operation was repeated once more. The DCM was evaporated to dryness, the extract was eventually dried 
Table 1. Chromatographic properties of the imino derivatives of (E,E,E)- 8,15,22-heptatriacontatrien-2-one and (E,E)-15,22heptatriacontadien-2-one (synthetic standards)

\begin{tabular}{|c|c|c|c|c|c|c|c|c|c|c|c|c|}
\hline \multirow[b]{2}{*}{$\begin{array}{l}\text { Imino } \\
\text { derivatives }\end{array}$} & \multicolumn{4}{|c|}{ Cyclopropyl } & \multicolumn{4}{|c|}{ iso-Propyl } & \multicolumn{4}{|c|}{ n-Propyl } \\
\hline & Yield & $\begin{array}{c}\mathrm{RRT}^{\mathrm{a}} \\
\mathrm{Me}\end{array}$ & $\begin{array}{l}\mathrm{RRT}^{\mathrm{a}} \\
\text { Phe }\end{array}$ & $\mathrm{McL} / \alpha^{\mathrm{b}}$ & Yield & $\begin{array}{c}\mathrm{RRT}^{\mathrm{a}} \\
\mathrm{Me}\end{array}$ & $\begin{array}{c}\mathrm{RRT}^{\mathrm{a}} \\
\text { Phe }\end{array}$ & $\mathrm{McL} / \alpha^{\mathrm{b}}$ & Yield & $\begin{array}{c}\mathrm{RRT}^{\mathrm{a}} \\
\mathrm{Me}\end{array}$ & $\begin{array}{c}\mathrm{RRT}^{\mathrm{a}} \\
\text { Phe }\end{array}$ & $\mathrm{McL} / \alpha^{\mathrm{b}}$ \\
\hline Me37:3 & 96 & 1.08 & 1.28 & 0.6 & 53 & 1.03 & 1.10 & 7.9 & 16 & 1.06 & 1.19 & 3.0 \\
\hline Me37:2 & 95 & 1.08 & 1.28 & 0.8 & 49 & 1.03 & 1.10 & 8.5 & 15 & 1.06 & 1.19 & 3.1 \\
\hline
\end{tabular}

${ }^{a} \mathrm{RRT}$, relative retention time with respect to the parent alkenones calulated with a $100 \%$ methylpolysiloxane (Me) or a $5 \%$ phenyl $95 \%$ methylpolysiloxane (Phe) column.

${ }^{b}$ Ratio between the ions of McLafferty rearrangement and cleavage at $\alpha$ position from the imino group.

with sodium sulfate, and dissolved in toluene for GC-MS analysis.

\section{Instrumental Analysis}

GC-MS was performed with a Trace GC-MS and data processed with Xcalibur software (Thermo Instruments, Manchester, UK). The carrier gas was $\mathrm{He}$ at a flow of 1 $\mathrm{mL} / \mathrm{min}$. Injection port, transfer line and ion source were heated at 300,270 , and $200{ }^{\circ} \mathrm{C}$, respectively. The mass spectrometer was operated in EI mode $(70 \mathrm{eV})$, scanning between $\mathrm{m} / z 50$ and $700 \mathrm{Da}$ at 1 or 1.5 cycles/s. Samples were injected in toluene in two different columns. A $50 \mathrm{~m}$ capillary column coated with 100\% methyl polysiloxane (CPSil5 CB, $0.25 \mathrm{~mm}$ i.d. with a film thickness of $0.12 \mu \mathrm{m}$; Chrompak-Varian) and a $60 \mathrm{~m}$ capillary column coated with $5 \%$ phenyl- 95\% methylpolysiloxane (HP-5, $0.25 \mathrm{~mm}$ i.d., and $0.25 \mu \mathrm{m}$ film thickness; Hewlett Packard, CA). The temperature program of the first column started at $90{ }^{\circ} \mathrm{C}(1 \mathrm{~min})$, increased at a rate of $20^{\circ} \mathrm{C} / \mathrm{min}$ to $170^{\circ} \mathrm{C}$, and then to $280^{\circ} \mathrm{C}$ at a rate of $6{ }^{\circ} \mathrm{C} / \mathrm{min}$ with a holding time of 25 min, and finally to $310^{\circ} \mathrm{C}$ at $10^{\circ} \mathrm{C} / \mathrm{min}$ with a final holding time of $12 \mathrm{~min}$. The temperature program of the second column started at $90^{\circ} \mathrm{C}(1 \mathrm{~min})$, raised at $15^{\circ} \mathrm{C} / \mathrm{min}$ to $150{ }^{\circ} \mathrm{C}$, and then to $310^{\circ} \mathrm{C}$ at $4{ }^{\circ} \mathrm{C} / \mathrm{min}$ with a final holding time of $30 \mathrm{~min}$.

\section{Results and Discussion}

\section{Reaction Yields}

One important aspect for the derivatization of (E,E,E)8,15,22-heptatriacontatrien-2-one and (E,E)-15,22-heptatriacontadien-2-one is the elimination of water from the sample extracts and solvents. Examination of diverse desiccants showed that sodium sulfate is better than molecular sieves, since the former avoids adsorption of linear compounds. Thus, when using the latter, losses of $60 \%$ of $n$-tetracontane with respect to $n$-hexatriacontane were observed and several artifacts were formed. Obviously, these adsorption effects should be avoided since they may hinder the possibility of study of a significant proportion of the lipids present in the extracts and do not allow obtaining quantitative results when using $n$-alkanes as internal standards.

The reaction yields of these $C_{3}$ amines with the above mentioned synthetic alkenone standards were found to be $>95 \%, \sim 50 \%$, and $\sim 15 \%$ for the cyclopropyl-, isopropyl-, and $n$-propylamino derivatives, respectively (Table 1). Both di- and triunsaturated ketones gave similar yields for the cyclopropylamine. In contrast, better results for the triunsaturated alkenone were found in the reaction with the other two amines. These yield values agree with the relative base strength of the amines, since the formation reaction involves the sequential loss of the two amino protons [1]. $n$ Propylamine has a secondary carbon atom in position $\alpha$ relative to the nitrogen atom, and both cyclopropyl- and iso-propylamine have a tertiary carbon (one single $\mathrm{H}$ ) in this site. Of these last two, the higher degree of hydrogen substitution in the latter involves slightly higher base strength than in the former. Steric hindrance caused by the large-volume difference between the cyclopropyl and iso-propyl groups may also play a role for the observed yield differences.

\section{GC Properties of the $C_{3}$ Imino Derivatives}

All derivatives were tested in two chromatographic columns of different polarity (see the Experimental section). The relative retention time gap between the imine and its parent ketone was more significant in the polar $(5 \%$ phenyl) than in the apolar ( $100 \%$ methyl; Table 1) phase. In both columns, the smallest of the three groups, cyclopropyl, exhibited a higher retention index in relation to its parent alkenone. Again, this different chromatographic behavior can be due to the volume of the aliphatic radical group bound to the nitrogen, which may hinder the interaction with the column stationary phase. In this respect, although the elongated shape of the n-propyl chain may produce a higher exclusion volume around the nitrogen by rotation, its asymmetry may still allow higher interaction with the stationary phase than the branched acyclic amines. The iso-propyl group, albeit being less bulky, is more symmetrical around the nitrogen atom, which probably decreases the interactions with the column phase relative to the $n$-propyl group. The retention time difference between the iso-propylimine and the parent ketone is so small that there is co-elution between the two types of compounds. 

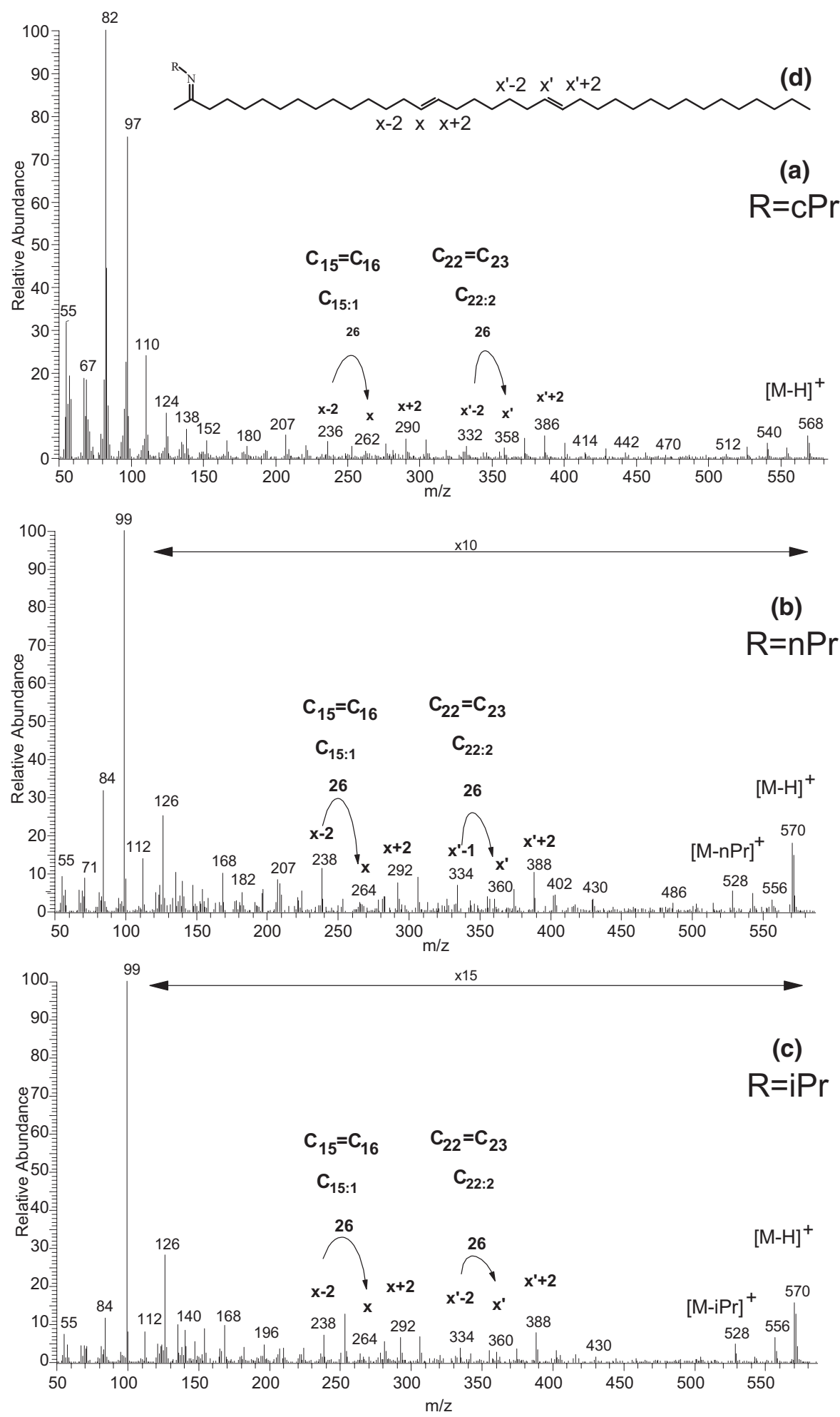

Figure 1. Mass spectra of N-cyclopropyl- (a), N-n-propyl- (b), and N-iso-propylimines (c), of (E,E)-15,22-heptatriacontadien-2-one (synthetic standard), (d) general structure of the imino derivatives showing the correspondences between double bond locations and mass fragments.

\section{Mass Spectra}

The mass spectra of the three $C_{3}$ imino derivatives (Figure 1) exhibit high intensities for the McLafferty rearrangement (Table 2). In the two acyclic imines, this ion is the base peak in both methyl- and ethylketones $(\mathrm{m} / \mathrm{z} 99$ and 113 , respectively). In the cyclopropylimines, the base peak corresponds to $\alpha$-cleavage from the imino group $(\mathrm{m} / z 82$ and 96 for the methyl and ethyl ketones, respectively) but 
Table 2. Diagnostic ions of the alkenones and their cyclopropyl-, iso-propyl- and n-propylimino derivatives from the samples analyzed in the present study

\begin{tabular}{|c|c|c|c|c|c|c|c|c|c|c|c|c|c|c|c|c|c|c|c|c|c|c|}
\hline \multirow[b]{2}{*}{ Ketone $^{a}$} & \multirow[b]{2}{*}{ Structure } & \multicolumn{3}{|c|}{ Ketones } & \multicolumn{8}{|c|}{ Cyclopropylimines } & \multicolumn{9}{|c|}{ iso-Propyl/n-propyl imines } & \multirow[b]{2}{*}{ Sample $^{f}$} \\
\hline & & $\begin{array}{c}\mathrm{RRT}^{\mathrm{b}} \\
37: 3\end{array}$ & $\begin{array}{l}\mathrm{M} \\
\mathrm{m} / \mathrm{z}\end{array}$ & $\begin{array}{l}\mathrm{M}-\mathrm{R}_{1}{ }^{\mathrm{C}} \\
\mathrm{m} / \mathrm{z}\end{array}$ & $\begin{array}{l}\text { RRT } \\
37: 3\end{array}$ & $\begin{array}{l}\mathrm{M} \\
\mathrm{m} / \mathrm{z}\end{array}$ & $\begin{array}{l}d \\
z\end{array}$ & $\begin{array}{c}\mathrm{M}-\mathrm{R}_{1}{ }^{\mathrm{C}} \\
\mathrm{m} / \mathrm{z}\end{array}$ & $\begin{array}{c}\mathrm{McL}^{\mathrm{e}} \\
\mathrm{m} / \mathrm{z}\end{array}$ & $\begin{array}{c}x \\
m / z\end{array}$ & $\begin{array}{l}\mathbf{x}^{\prime} \\
m / z\end{array}$ & $\begin{array}{l}x^{\prime \prime} \\
m / z\end{array}$ & $\begin{array}{l}x^{\prime \prime \prime} \\
m / z\end{array}$ & $\begin{array}{l}\mathrm{M} \\
\mathrm{m} / \mathrm{z}\end{array}$ & $\begin{array}{l}\alpha^{\mathrm{d}} \\
m / z\end{array}$ & $\begin{array}{c}\mathrm{M}-\mathrm{R}_{1}{ }^{\mathrm{c}} \\
\mathrm{m} / \mathrm{z}\end{array}$ & $\begin{array}{l}\mathrm{McL}{ }^{\mathrm{e}} \\
\mathrm{m} / \mathrm{z}\end{array}$ & $\begin{array}{c}\mathrm{x} \\
\mathrm{m} / \mathrm{z}\end{array}$ & $\begin{array}{l}\mathbf{x}^{\prime} \\
m / z\end{array}$ & $\begin{array}{l}x^{\prime \prime} \\
m / z\end{array}$ & $\begin{array}{l}X^{\prime \prime \prime} \\
m / z\end{array}$ & \\
\hline Me37:4 & $\begin{array}{l}8 \mathrm{E}, 15 \mathrm{E}, 22 \mathrm{E}, \\
29 \mathrm{E}\end{array}$ & 0.99 & 526 & 511 & 0.98 & 565 & 82 & 550 & 97 & 164 & 260 & 356 & 452 & 567 & 84 & 552 & 99 & 164 & 260 & 356 & 452 & $\begin{array}{l}\text { LT, LC, SB, WM, } \\
\text { AS, MAO, SK, } \\
\text { Eh }\end{array}$ \\
\hline Me37:3 & $8 \mathrm{E}, 15 \mathrm{E}, 22 \mathrm{E}$ & 1.00 & 528 & 513 & 1.00 & 567 & 82 & 552 & 97 & 164 & 260 & 356 & & 569 & 84 & 554 & 99 & 164 & 260 & 356 & & $\begin{array}{l}\text { LT, LC, SB, WM, } \\
\text { AS, MAO, SK, } \\
\text { Eh }\end{array}$ \\
\hline Me37:2 & $15 \mathrm{E}, 22 \mathrm{E}$ & 1.01 & 530 & 515 & 1.05 & 569 & 82 & 554 & 97 & 262 & 358 & & & 571 & 84 & 556 & 99 & 262 & 358 & & & $\begin{array}{l}\text { LT, LC, SB, WM, } \\
\text { AS, MAO, SK, } \\
\text { Eh }\end{array}$ \\
\hline Et38:4 & $\begin{array}{l}9 \mathrm{E}, 16 \mathrm{E}, 23 \mathrm{E}, \\
30 \mathrm{E}\end{array}$ & 1.07 & 540 & 511 & 1.05 & 579 & 96 & 550 & 111 & 178 & 274 & 370 & 466 & 581 & 98 & 552 & 113 & 178 & 274 & 370 & 466 & $\begin{array}{l}\text { LT, LC, SB, WM, } \\
\text { AS, MAO, SK, } \\
\text { Eh }\end{array}$ \\
\hline Me38:4 & $\begin{array}{l}8 \mathrm{E}, 15 \mathrm{E}, 22 \mathrm{E}, \\
29 \mathrm{E}\end{array}$ & 1.08 & 540 & 525 & 1.09 & 579 & 82 & 564 & 97 & 164 & 260 & 356 & 452 & 581 & 84 & 566 & 99 & 164 & 260 & 356 & 452 & Eh \\
\hline Et38:3 & $9 \mathrm{E}, 16 \mathrm{E}, 23 \mathrm{E}$ & 1.09 & 542 & 513 & 1.07 & 581 & 96 & 552 & 111 & 178 & 274 & 370 & & 583 & 98 & 554 & 113 & 178 & 274 & 370 & & $\begin{array}{l}\text { LT, LC, SB, WM, } \\
\text { AS, MAO, SK, } \\
\text { Eh }\end{array}$ \\
\hline Мe38:3 & $8 \mathrm{E}, 15 \mathrm{E}, 22 \mathrm{E}$ & 1.10 & 542 & 527 & 1.11 & 581 & 82 & 566 & 97 & 164 & 260 & 356 & & 583 & 84 & 568 & 99 & 164 & 260 & 356 & & $\begin{array}{l}\text { SB, WM, AS, } \\
\text { MAO, SK, Eh }\end{array}$ \\
\hline Et38:2 & $16 \mathrm{E}, 23 \mathrm{E}$ & 1.10 & 544 & 515 & 1.08 & 583 & 96 & 554 & 111 & 276 & 372 & & & 585 & 98 & 556 & 113 & 276 & 372 & & & $\begin{array}{l}\text { LT, LC, SB, WM, } \\
\text { AS, MAO, SK, } \\
\text { Eh }\end{array}$ \\
\hline Me38:2 & $15 \mathrm{E}, 22 \mathrm{E}$ & 1.11 & 544 & 529 & 1.13 & 583 & 82 & 568 & 97 & 262 & 358 & & & 585 & 84 & 570 & 99 & 262 & 358 & & & $\begin{array}{l}\text { SB, WM, AS, } \\
\text { MAO, SK, Eh }\end{array}$ \\
\hline Et39:4 & $\begin{array}{l}9 \mathrm{E}, 16 \mathrm{E}, 23 \mathrm{E}, \\
\quad 30 \mathrm{E}\end{array}$ & 1.14 & 562 & 533 & 1.17 & 601 & 96 & 572 & 111 & 178 & 274 & 370 & 466 & 603 & 98 & 574 & 113 & 178 & 274 & 370 & 466 & Eh \\
\hline Me39:4 & $\begin{array}{l}8 \mathrm{E}, 15 \mathrm{E}, 22 \mathrm{E} \\
\quad 29 \mathrm{E}\end{array}$ & 1.17 & 554 & 539 & 1.23 & 593 & 82 & 578 & 97 & 164 & 260 & 356 & 452 & 595 & 84 & 580 & 99 & 164 & 260 & 356 & 452 & $\begin{array}{l}\text { LT, LC, SB, WM, } \\
\text { AS, MAO, SK, } \\
\text { Eh }\end{array}$ \\
\hline Et39:3 & $9 \mathrm{E}, 16 \mathrm{E}, 23 \mathrm{E}$ & 1.18 & 556 & 527 & 1.19 & 595 & 96 & 566 & 111 & 178 & 274 & 370 & & 597 & 98 & 568 & 113 & 178 & 274 & 370 & & $\begin{array}{l}\text { SB, WM, AS, } \\
\text { MAO, SK, Eh }\end{array}$ \\
\hline Ме39:3 & $8 \mathrm{E}, 15 \mathrm{E}, 22 \mathrm{E}$ & 1.19 & 556 & 541 & 1.25 & 595 & 82 & 580 & 97 & 164 & 260 & 356 & & 597 & 84 & 582 & 99 & 164 & 260 & 356 & & $\begin{array}{l}\text { LT, LC, SB, WM, } \\
\text { AS, MAO, SK, } \\
\text { Eh }\end{array}$ \\
\hline Et39:2 & $16 \mathrm{E}, 23 \mathrm{E}$ & 1.20 & 558 & 529 & 1.22 & 597 & 96 & 568 & 111 & 276 & 372 & & & 599 & 98 & 570 & 113 & 276 & 372 & & & $\begin{array}{l}\text { SB, WM, AS, } \\
\text { MAO, SK, Eh }\end{array}$ \\
\hline Ме39:2 & $15 \mathrm{E}, 22 \mathrm{E}$ & 1.20 & 558 & 543 & 1.27 & 597 & 82 & 582 & 97 & 262 & 358 & & & 599 & 84 & 584 & 99 & 262 & 358 & & & $\begin{array}{l}\text { LT, LC, SB, WM, } \\
\text { AS, MAO, SK, } \\
\text { Eh }\end{array}$ \\
\hline Et40:3 & $9 \mathrm{E}, 16 \mathrm{E}, 23 \mathrm{E}$ & 1.22 & 570 & 541 & 1.36 & 609 & 96 & 580 & 111 & 178 & 274 & 370 & & 611 & 98 & 582 & 113 & 178 & 274 & 370 & & LT, LC \\
\hline Et40:2 & $16 \mathrm{E}, 23 \mathrm{E}$ & 1.24 & 572 & 543 & 1.38 & 611 & 96 & 582 & 111 & 276 & 372 & & & 613 & 98 & 584 & 113 & 276 & 372 & & & LT, LC \\
\hline
\end{tabular}

aMe: Methylketone, Et: Ethylketone.

${ }^{\mathrm{b} R R T}$ : relative retention index to Mc37:3 (row 2) as free ketone or iminoderivative.

${ }^{\mathrm{c}} \mathrm{M}-\mathrm{R}_{1}$ : fragment due to the $\alpha$-cleavage to the carbonyl or the imino groups, $\mathrm{R}_{1}=\mathrm{Me}$ or Et.

${ }^{\mathrm{d}} \alpha$ : fragment containing the imino group after cleavage at $\alpha$ position.

'Mc: McLafferty type rearrangement. $x_{,} x^{\prime}, x^{\prime \prime}, x^{\prime \prime \prime}$ indicate the relative position of the unsaturations according to the double bond positions of the second column

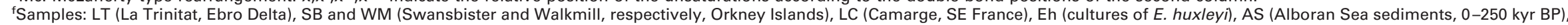

MAO (Mid Atlantic Ocean Surface Waters), SK (waters from Skagerrak Strait, DK) 
(a)

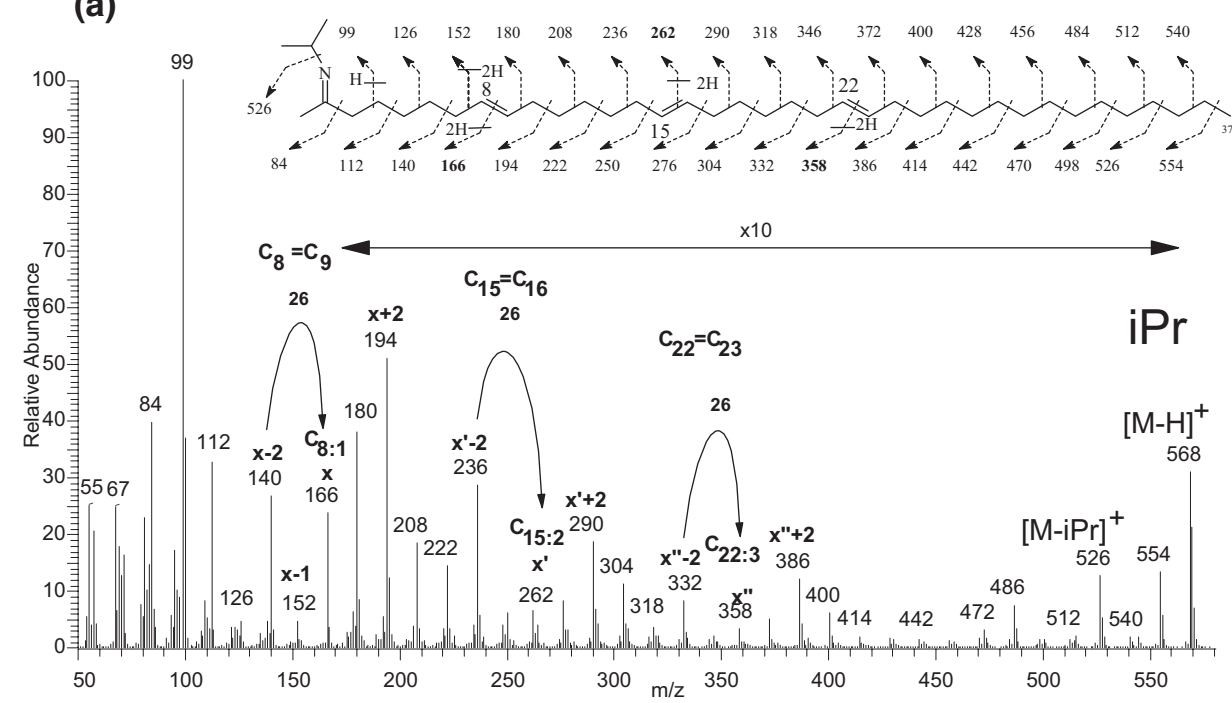

(b)

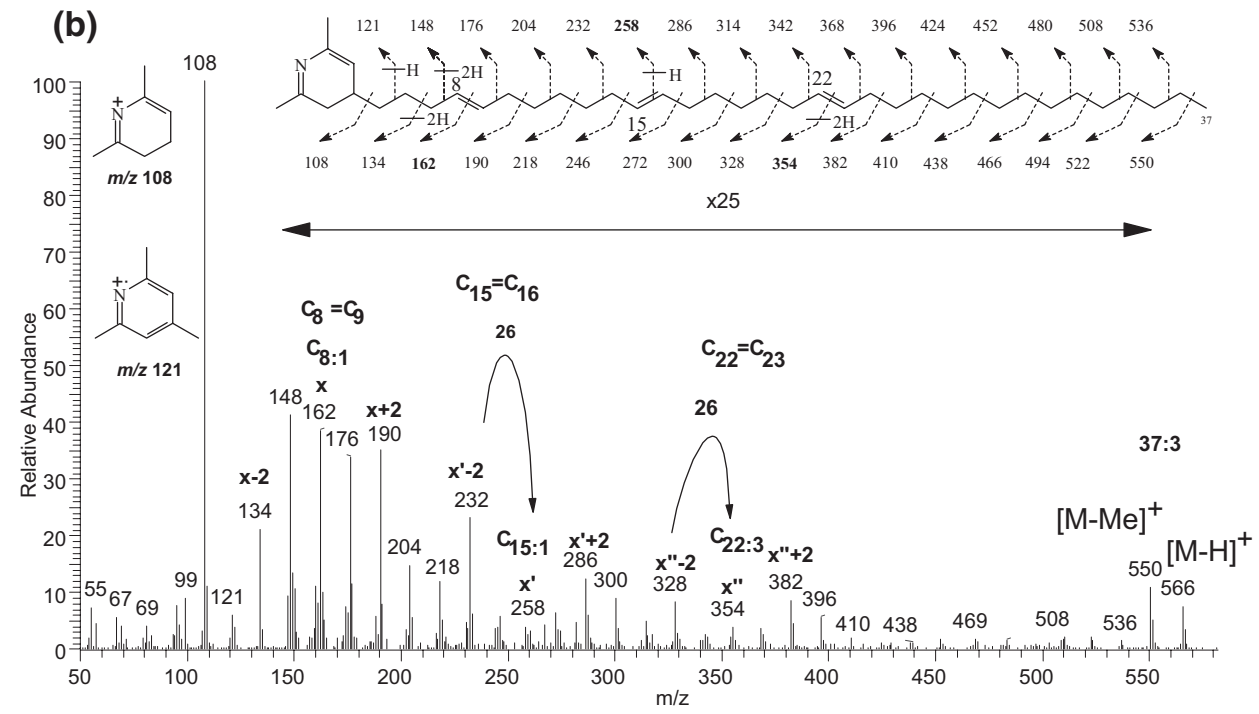

Figure 2. Mass spectra of the N-iso-propylimine of 8E,15E,22E-heptatriacontatrien-2-one (a) and one artifact formed during the reaction, a 4-alkyl-2,6-dimethylpyridine derivative (b), at much lower concentration.

the ion of the McLafferty rearrangement is still high $(\mathrm{m} / \mathrm{z}$ 97 and 111, respectively). The relative intensities of these two ions $(\mathrm{McL} / \alpha)$ exhibit a reverse trend with the previously reported retention time differences between imino derivatives and precursor alkenones (Table 1). Lower steric hindrance involves higher intensities of the fragments generated by $\alpha$-cleavage than those generated by McLafferty rearrangement, and higher retention time differences between the derivatives and the precursor alkenones.

Formation of artifacts was observed among the products obtained after derivatization with iso-propylamine. The most abundant have been tentatively identified as 4-alkyl-2,6-dimethyl-pyridines, where the alkyl group corresponds to the long-chain side of the alkenone skeleton spanning from $C_{5}$ in the methyl ketones and $C_{6}$ in the ethyl ketones. The mass spectra of both iso- propylimine and 4-alkyl-2,6-dimethylpyridine derivatives of (E,E,E)-8,15,22-heptatriacontatrien-2-one are compared in Figure 2. The double-bond positions in the original alkenones can be identified in both cases. However, the complexity of the chromatograms resulting from the formation of these two types of derivatives in the same extract argues against the use of isopropylamine for alkenone derivatization.

The mass spectra of the cyclopropylimino derivatives of (E,E,E)-8,15,22-heptatriacontatrien-2-one and $(\mathrm{E}, \mathrm{E}, \mathrm{E}, \mathrm{E})-9,16,23,30$-octatriacontatetraen-3-one are shown in Figure 3. As in the previously reported imino derivatives [1], they exhibit homologous series of evenelectron fragments separated by $14 \mathrm{Da}$. The series start at $\mathrm{m} / \mathrm{z} 82$ and 96 for the methyl and ethyl imines, respectively. These fragments can be used as diagnostic ions for elucidation of double-bond positions. They 

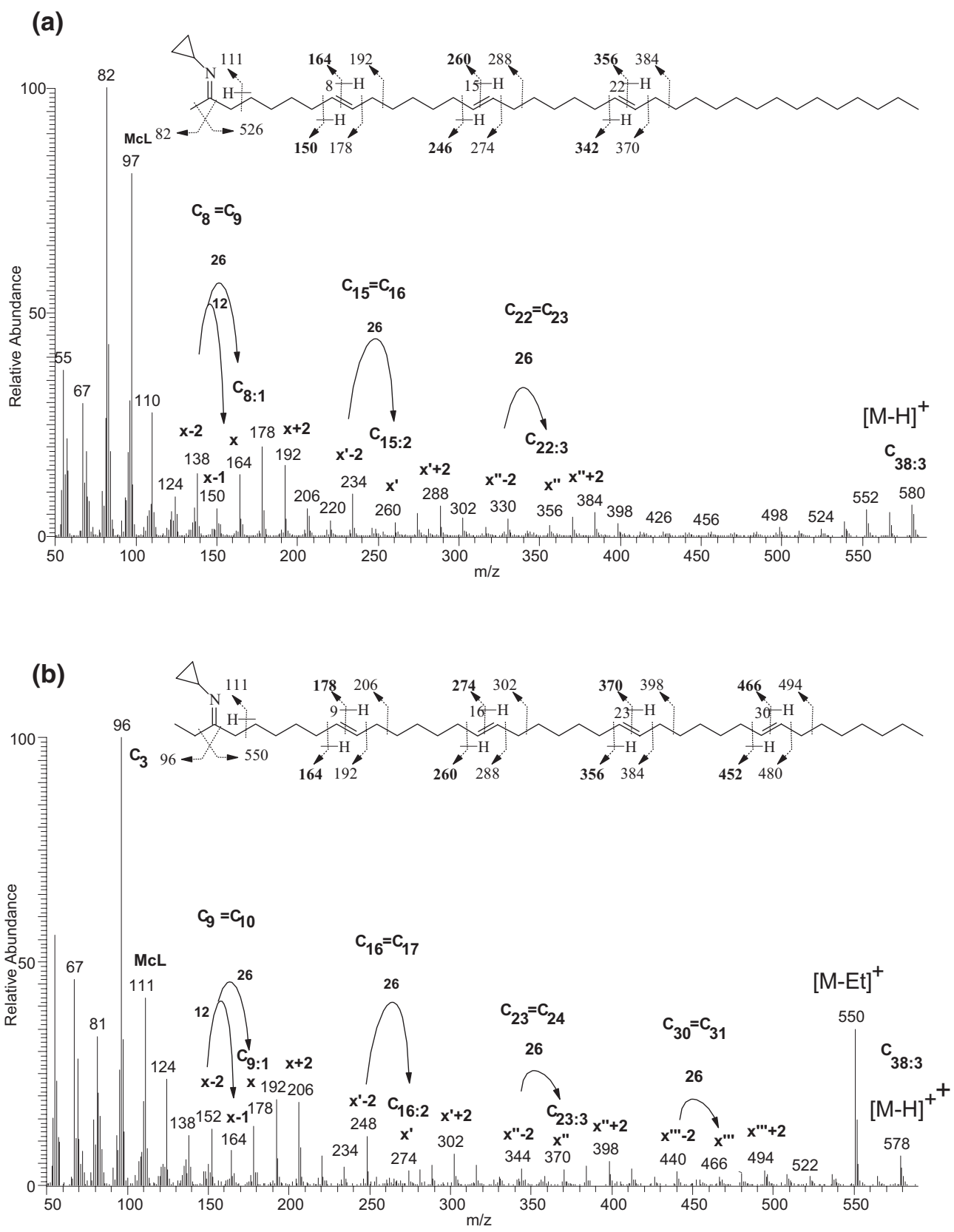

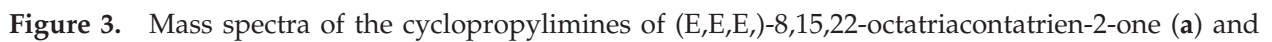
(E,E,E,E)-9,16,23,30-octatriacontatetraen-3-one (b) from a culture of E. huxleyi.

exhibit higher relative intensity in the mass spectra of the cyclopropyl imino derivatives than in those of the derivatives with the acyclic amines. The molecular ion $\left(\mathrm{M}^{+}\right)$is less intense than the even electron fragment involving hydrogen loss $\left([\mathrm{M}-\mathrm{H}]^{+}\right)$.

The fragments corresponding to the positions of the unsaturations are indicated in the mass spectra by the letter $\mathrm{x}$ with comma superscripts depicting the different double bonds $\left(x, x^{\prime}, x^{\prime \prime}, x^{\prime \prime \prime}\right)$ in ascending order along the aliphatic chain (Figures 1-3). One distinct feature of these derivatives is that around the double-bond positions, the fragments having two more or less carbon atoms ( $x+2$ and $x-2$, respectively) are more abun- dant than the fragment of cleavage at the unsaturation site. This intensity pattern of fragments brackets the position of the double-bond facilitating its identification. In addition, the differences between the $x-2$ and $x$ fragments (or $x^{\prime}-2$ and $x^{\prime}$, etc) correspond to $m / z 26$, which afford an additional feature for the location of the double-bond sites that are indicated by $\mathrm{x}$ (or $\mathrm{x}^{\prime}$, etc). To achieve these fragmentations, there must be a previous migration of the double-bond as in $x-2$. Since this process involves two stages, migration and cleavage, the intensity of the mass fragments is attributed to the high stability provided by the conjugated double bonds formed in the fragment bearing the radical. 
In the case of cyclopropylimines, fragmentation leading to $x-1$ type ions (Figure 3 ) shows a high abundance in the vicinity of the imino group. This fragment is not intense with cyclopentyl and phenylimines [1]. A similar limited double-bond migration is also observed in the formation 2-alkenylbenzoxazole derivatives from fatty acids [18].

\section{Double-Bond Location Using the Mass Spectral Data of Cyclopropylimines}

Location of double-bond positions is straightforward after examination of the the above indicated fragmentation patterns. The intensity of the mass fragments at $x$ -2 and $x+2$ is higher than those of the homologous series separated by $14 \mathrm{Da}$ and are easy to recognize. Each pair of $x-2$ and $x+2$ fragments is, therefore, bracketing the fragment $x$ that indicates the position of the double-bond. For example, in the cyclopropylimino derivative of (E,E,E,E)-9,16,23,30-octatriacontatetraen-3one (Figure 3b) the pairs of $m / z 152$ and $206(x-2$, $\mathrm{x}+2$, respectively), $m / z 248$ and $302\left(\mathrm{x}^{\prime}-2, \mathrm{x}^{\prime}+2\right), m / z$ 344 and $398\left(x^{\prime \prime}-2, x^{\prime \prime}+2\right)$, and $m / z 440$ and $494\left(x^{\prime \prime \prime}-2\right.$, $\left.\mathrm{x}^{\prime \prime \prime}+2\right)$ correspond to the double-bond at positions, 9, 16,23 , and 30 , respectively. In addition, $x$ and $x-2$ exhibit a difference of $26 \mathrm{Da}$, e.g., the pairs $\mathrm{m} / \mathrm{z} 152$ and $178\left(\mathrm{x}-2, \mathrm{x}\right.$, respectively), $m / z 248$ and $274\left(\mathrm{x}^{\prime}-2, \mathrm{x}^{\prime}\right)$, $m / z 344$ and $370\left(x^{\prime \prime}-2, x^{\prime \prime}\right)$ and $m / z 440$ and 466 $\left(x^{\prime \prime \prime}-2, x^{\prime \prime \prime}\right)$ for the positions of the double bonds at 9 , 16,23 , and 30 , respectively, in the tetraunsaturated alkenone shown in Figure 3b. These two groups of mass fragment pairs provide very distinct features for the identification of the positions of the unsaturations.

In addition, the double bonds located nearby the imino group exhibit one additional intense mass fragment at $\mathrm{x}-1$ showing $14 \mathrm{Da}$ of difference from $\mathrm{x}$, e.g., $m / z 164$ and 178 for $x-1$ and $x$ in $(E, E, E, E)-9,16,23,30-$ octatriacontatetraen-3-one (Figure $3 b$ ), which corresponds to the unsaturation at position 9. This fragment provides an additional feature for the identification of the double-bond closest to the imino group. This additional $x-1$ fragment is formed by migration [19] or cyclization due to the closer distance between this double-bond and the nitrogen atom than the other unsaturations.

\section{Reassessment of the Structures of the Alkenones Present in Natural Environments}

The alkenone distributions identified so far can be grouped in two types. Type $\mathrm{A}$ is composed by $\mathrm{C}_{37}$ methylketones, $\mathrm{C}_{40}$ ethylketones, $\mathrm{C}_{38}$ methyl and ethylketones, and $\mathrm{C}_{39}$ methyl and ethylketones. This group is the one most commonly found in marine waters, sediments, and in a few nonmarine environments. This distribution is synthesized by the Haptophycean species E. huxleyi, Gephyrocapsa oceanica, and several strains of the genus Isochrysis [3]. Type B, the less common, is characterized by a well defined relationship between carbonyl position and chain parity; that is, methyl and ethyl ketones for the odd and even carbon number homologues, respectively. To date, the only known algal precursor of this distribution is Chrysotila lamellosa $[3,20]$ Type B alkenones are found in sediments from freshwater lakes, hypersaline ponds, and ancient sediments such as those from the Cretaceous (AptianAlbian 100-120 M y) [4, 21]. In this last case, the distribution is only represented by diunsaturated homologues.

Representative samples of these two distributions have been analyzed in the present study (Table 2). The strain of E. huxleyi contains all $\mathrm{C}_{37}-\mathrm{C}_{39}$ homologues belonging to Type $A$, with the exception of the $C_{40}$ compounds that have not been found. The hypersaline ponds from La Trinitat and La Camargue contain the Type B distribution.

All the alkenones analyzed in this work share the common structural feature of having the double bonds at the same carbon atom distance from the carbonyl group (Table 2). This common feature is also observed in alkenones synthesized by ancient haptophyte species different from those living in the present times [22], since the marine sediments from the Alboran Sea included in the present study cover an age span of the last $250 \mathrm{ky}$, the last two glacial-interglacial periods, and do not show any structural differences between the alkenones in the warmest or coldest episodes or in relation to salinity changes [6].

This result represents a correction of previously assumed criteria on double-bond locations for these alkenones. Early studies on double-bond location of these compounds were based on synthesis of $(\mathrm{E}, \mathrm{E})-$, 15,22-heptatriacontadien-2-one, (E,E,E,)-8,15,22-heptatriacontatrien-2-one, and (E,E,E,E,)-8,15,22,29-heptatriacontatetraen-2-one [23], and double-bond oxidation and diol derivatization of (E,E,)-15,22-heptatriacontadien-2one, (E,E,E,)-8,15,22-heptatriacontatrien-2-one, (E,E)16,23-octatriacontadien-3-one, and (E,E,E)-9,16,23-octatriacontatrien-3-one [8]. With those results in hand, it was established that double-bond position of the nonstudied homologues was determined from the position of the methyl end, e.g., $\omega-8, \omega-15, \omega-22$, and $\omega-29$. However, the location of the unsaturations in all five alkenones analyzed can be described by either counting from the methyl end or the carbonyl group. In the present study, direct examination of the double-bond position in many more alkenones (17 homologues, Table 2) with cyclopropylimino derivatization shows that the unsaturations are effectively separated in intervals of five methylene groups, but counting from the carbonyl functionality, e.g., 7, 14, 21, or 28 carbon atoms.

\section{Alkyl Alkenoates}

Since the earlier reports on alkenone occurrence in sediments and cultured microalgae, the presence of 
Table 3. Alkenoates identified in the Camargue sediments

\begin{tabular}{|c|c|c|c|c|c|c|c|c|c|c|}
\hline \multirow[b]{3}{*}{ Acid } & \multicolumn{3}{|c|}{ Alkenoate } & \multicolumn{7}{|c|}{ Oxazoline } \\
\hline & & \multicolumn{2}{|c|}{ M-OR } & \multirow[b]{2}{*}{$\mathrm{M}$} & \multirow[b]{2}{*}{$m / z$} & \multirow[b]{2}{*}{$m / z$} & \multirow{2}{*}{$\begin{array}{c}\mathrm{x} \\
m / z\end{array}$} & \multirow{2}{*}{$\begin{array}{c}\mathbf{x}^{\prime} \\
m / z\end{array}$} & \multirow{2}{*}{$\begin{array}{l}\mathbf{x}^{\prime \prime} \\
m / z\end{array}$} & \multirow{2}{*}{$\begin{array}{l}\mathbf{x}^{\prime \prime \prime} \\
m / z\end{array}$} \\
\hline & Structure & $\mathrm{M}$ & $m / z$ & & & & & & & \\
\hline FAEE36:4 & $7,14,21,28$ & 556 & 511 & 581 & 113 & 126 & 180 & 276 & 372 & 468 \\
\hline FAEE36:3 & $7,14,21$ & 558 & 513 & 583 & 113 & 126 & 180 & 276 & 372 & \\
\hline FAEE36:3 & $14,21,28$ & 558 & 513 & 583 & 113 & 126 & 278 & 374 & 470 & \\
\hline FAEE36:2 & 14,21 & 560 & 515 & 585 & 113 & 126 & 278 & 374 & & \\
\hline
\end{tabular}

structurally related methyl and ethyl esters of mainly 36 carbon atoms was described $[24,25]$. Among the samples herein studied, the presence of methyl and ethyl hexatriacontenoates was examined after derivatization into 4,4-dimethyloxazolines [17] for location of the double-bond positions. Table 3 shows the structural information obtained from the mass spectra of the fatty acid derivatives. It must be pointed out that in the derivatization reaction, both methyl and ethyl ester groups are replaced by the same type of heterocycle and cannot be differentiated upon GC analysis. Thus, in the absence of previous separation, e.g., by column chromatography, the information on number of unsaturations and their location has been attributed to the dominant ethyl esters.

Previous information on methyl and ethyl hexatriaconta-14,21-dienoates from marine sediments and cultures was obtained by examination of the mass spectra of trimethylsilyloxy derivatives of the 1,2-diols formed by $\mathrm{OsO}_{4}$ derivatization [24]. The present results based on dimethyloxazoline derivatives agree with the assignment of double-bond locations in this previous study, and allow the identification, for the first time, of the locations of the unsaturations in the hexatriacontatrienoic and hexatriacontatetraenoic acids listed in Table 3. Three of the alkenoic acids reported in this table have the double bonds in positions equivalent to alkenones with the same degree of unsaturation when counting the carbon atoms from the carboxylic group. Accordingly, locations $7,14,21$, and 28 in the alkenoate correspond to $8,15,22$, and 29 in the tetraunsaturated methylketone and to $9,16,23$, and 30 on the ethylketone. This suggests that the enzymes involved in the synthesis of alkenones and alkenoates may take the carbonyl group as a reference for double-bond formation in exactly those relative positions.

Having in mind this parallelism in double-bond spacing, the finding of a new isomer, hexatriaconta14,21,28-trienoic acid (Figure 4), in relatively high concentrations suggest that triunsaturated alkenones with double bonds in equivalent positions, e.g., 15, 22, and 29 or 16, 23, and 30 in methyl or ethylketones, respectively, should be present. However, they have not been identified so far. As shown in Table 2, all known alkenones have their double bonds in series separated in intervals of five methylene groups that start to count at six carbon atoms from the keto- group in the tri- and tetraunsaturated homologues, and at thirteen carbon atoms in the diunsaturated homologues. Thus, a higher variety of double-bond locations is observed in alkenoates than alkenones within this pattern of seven carbon atom spacing. However, possible identifications of alkenones with unsaturations located in other sites cannot be excluded in future studies.

\section{Conclusions}

$n$-Propylamine, iso-propylamine, and cyclopropylamine can be successfully used to prepare imines for the identification of double-bond locations in di-, tri-, and tetraunsaturated alkenones. These $C_{3}$ amines provide significant reductions in retention time and higher sensitivities than the $\mathrm{C}_{5}$ amines described in previous studies [1]. However, iso-propylamine leads to the formation of other compounds besides the expected iso-propylimines, e.g., 4-alkyl-2,6-dimethylpyridines, which gives rise to complex GC traces and hinder the use of these derivatives.

No byproducts have been observed in the use of cyclopropylamine. This compound is the one providing better recoveries and higher GC retention time differences between the imino derivatives and the precursor alkenones. It is, therefore, recommended as the reagent of choice for double-bond location in alkenones. Its imino derivatives can be prepared using anhydrous sodium sulfate instead of molecular sieves for water elimination, which prevents adsorption of linear compounds and formation of artifacts.

Examination of a large group of alkenones from cultures of E. huxleyi, water particles, and recent and ancient sediments show that two types of alkenone distributions are found; one is constituted of $C_{37}$ methylketones, $\mathrm{C}_{40}$ ethylketones, and $\mathrm{C}_{38}$ and $\mathrm{C}_{39}$ methyl and ethylketones (Type A), and the other by methyl odd carbon number $\left(\mathrm{C}_{37}\right.$ and $\left.\mathrm{C}_{39}\right)$ and ethyl even carbon number alkenones $\left(C_{38}\right.$ and $\left.C_{40}\right)$ (Type $B$ ). The use of cyclopropylamine for the identification of double-bond position shows that in both series, unsaturations are separated in intervals of five methylene groups and can be located by counting $7,14,21$, or 28 positions from the carbonyl functionality, e.g., 8, 15, 22, and 29 and 9, 16, 23, and 30 in methyl- and ethylketones, respectively. This result represents a correction from previous as- 


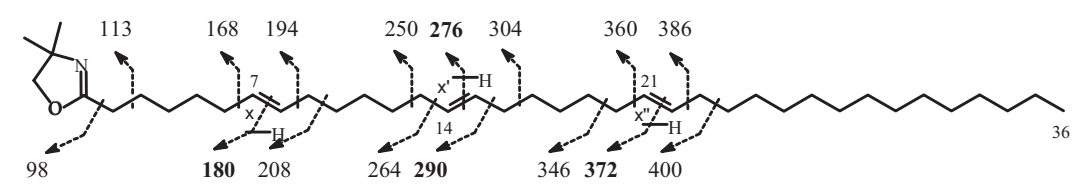

(a)

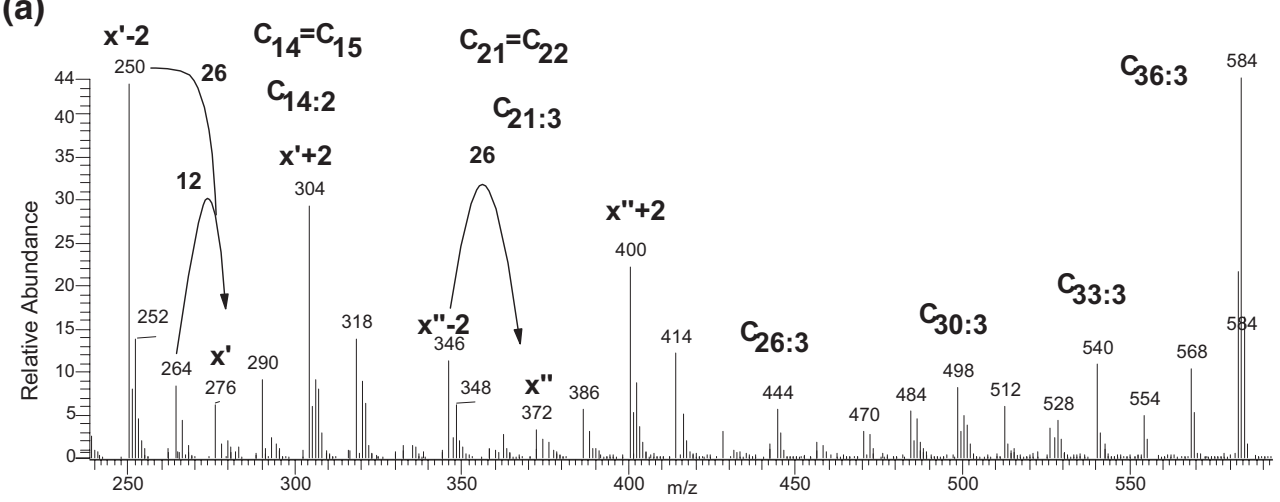

(b)
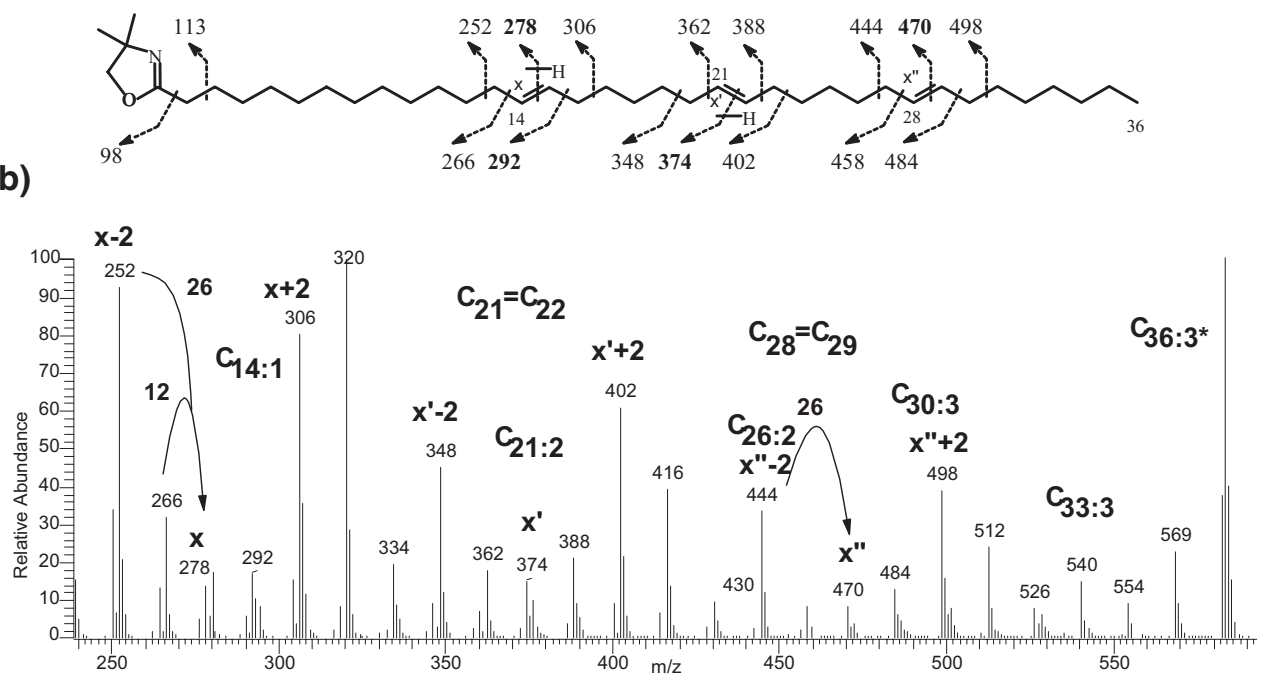

Figure 4. Mass spectra of the oxazoline derivatives of hexatriaconta-7,14,21-trienoate and hexatriaconta-14,21,28-trienoate. Note that the fragmentation for double-bond at position 7 is not included in the figure.

sumptions in which double-bond spacing was considered to be situated by reference to the methyl end.

Elucidation of double-bond positions in hexatriacontenoates by 4,4-dimethyloxazoline derivatization showed that these compounds also have they unsaturations separated in intervals of five methylene groups and counting by reference to the carbonyl group. The concurrence of both series of isomers in compounds of different oxygen functionalities indicates that the precursor haptophyceae species have a major biosynthetic pathway leading to the formation of these lipids. The finding, for the first time, of hexatriaconta-14,21,28-trienoic acid and the absence of a triunsaturated alkenone with double bonds in equivalent positions illustrates a higher variety of double-bond locations in alkenoates than alkenones within this pattern of seven carbon atom spacing.

\section{Acknowledgments}

The authors thank Professor J. R. Maxwell, University of Bristol, for the synthetic alkenone standards. They thank Drs. Belén Martrat, Tirso García de Oteyza, and Anja Kirch for providing valuable samples. Dr. Roser Chaler and Dori Fanjul are acknowledged for technical support. JFL thanks the Spanish Council for Scientific Research (CSIC) for an I3P grant. The authors acknowledge financial support from the EU Projects PACLIVA (EVK2CT2002-00143) and HERMES (GOCE-CT-2005-511234).

\section{References}

1. López, J. F.; Grimalt, J. O. Phenyl- and cyclopentylimino derivatization for double bond location in unsaturated C37-C40 alkenones by GC-MS. J. Am. Soc. Mass Spectrom. 2004, 15, 1161-1172.

2. Prahl, F. G.; Wakeham, S. G. Calibration of unsaturation patterns in long-chain ketone compositions for palaeotemperature assessment. Nature 1987, 330, 367-376.

3. Marlowe, I. T. Lipids as palaeoclimatic indicators; Ph.D. Thesis, University of Bristol, 1984, p 273. 
4. Brassell, S. C.; Dumitrescu, M. Recognition of alkenones in a lower Aptian porcellanite from the west-central Pacific. Org. Geochem. 2004, 35, 181-188.

5. Cacho, I.; Grimalt, J. O.; Pelejero, C.; Canals, M.; Sierro, F. J.; Flores, J. A.; Shackleton, N. J. Dansgaard-Oeschger and Heinrich event imprints in Alboran Sea paleotemperatures. Paleoceanography 1999, 14, 698-705.

6. Martrat, B.; Grimalt, J. O.; Lopez-Martinez, C.; Cacho, I.; Sierro, F. J.; Flores, J. A.; Zahn, R.; Canals, M.; Curtis, J. H.; Hodell, D. A. Abrupt temperature changes in the western Mediterranean over the past 250,000 years. Science 2004, 306, 1762-1765.

7. Liu, Z.; Herbert, T. D. High-latitude influence on the eastern equatorial Pacific climate in the early Pleistocene epoch. Nature 2004, 427, 720-723.

8. De Leeuw, J. W. Meer, F. W. V. D. Rijpstra, W. I. C. Schenck, P. A. On the occurrence and structural identification of long chain unsaturated ketones and hydrocarbons in sediments. Douglas, A. G.; Maxwell, J. R., Eds.; In Advances in Organic Geochemistry; Pergamon Press: Oxford, 1980, 211-217.

9. Xu, L.; Reddy, C. M.; Farrington, J. W.; Frysinger, G. S.; Gaines, R. B.; Johnson, C. G.; Nelson, R. K.; Eglinton, T. I. Identification of a novel alkenone in Black Sea sediments. Org. Geochem. 2001, 32, 633-645.

10. Yruela, I.; Barbé, A.; Grimalt, J. O. Determination of double bond position and geometry in linear and highly branched hydrocarbons and fatty acids from gas chromatography-mass spectrometry of epoxides and diols generated by stereospecific resin hydration. J. Chromatogr. Sci. 1990, 28, 421-427

11. Rechka, J. A.; Maxwell, J. R. Unusual long chain ketones of algal origin. Tetrahedron Lett. 1988, 29, 2599-2600.

12. de Wit, R; Grimalt, J. O. Microbial ecosystems in Spanish Coastal Salinas: An ecological and geochemical study of biomarkers. Limnetica $1992,8,205-212$.

13. Fourcans, A.; Garcia de Oteyza, T.; Wieland, A.; Sole, A.; Diestra, E.; van Bleijswijk, J.; Grimalt, J. O.; Kühl, M.; Esteve, I.; Muyzer, G.; Caumette, P.; Duran, R. Characterization of functional bacterial groups in a hypersaline microbial mat community (Salins-de-Giraud, Camarge, France). FEMS Microbiol. Ecol. 2004, 51, 55-70.

14. Wieland, A.; Kühl, M.; McGowan, L.; Fourcans, A.; Duran, R.; Caumette, P.; Garcia de Oteyza, T.; Grimalt, J. O.; Sole, A.; Diestra, E.; Esteve, I.; Herbert, R. A. Microbial mats on the Orkney Islands revisited:
Microenvironment and microbial community composition Microbiol. Ecol. 2003, 46, 371-390.

15. Kirch, A. Untersuchungen zur Rekonstruktion des Partialdruckes von Kohlendioxid anhand von Coccolithophoridenblüten im Nordatlantik: Biomarker Alkenone und deren Kohlenstoffisotopie; Ph.D. Dissertation, Mathematisch-Naturwissenschaftliche Fakultät der Christian-Albrechts-Universität Kiel, 2004; p 224.

16. Mansour, M. P.; Volkman, J. K.; Holdsworth, D. G. Jackson, A. E. Blackburn, S. I. Very-long-chain (C28) highly unsaturated fatty acids in marine dinoflagellates. Phytochemistry 1999, 50, 541-548.

17. Zhang, J. Y.; Yu, X. J.; Huang, Z. H. Chemical modification in mass Spectrom. IV. 2-Alkenyl-4,4-dimethyloxazolines as derivatives for the double bond location of long-chain fatty acids. Biomed. Environ. Mass Spectrom. 1988, 15, 33-44.

18. Yu, Q.; Zhang, J.; Huang, Z. A novel approach to double bond location in long-chain olefinic acids: The mass spectra of 2-alkenylbenzoxazoles. Biomed. Environ. Mass Spectrom. 1986, 13, 211-216.

19. Spitzer, V. Structure analysis of fatty acids by gas chromatography-low resolution electron impact mass spectrometry of their 4,4-dimethyloxazoline derivatives-A review. Prog. Lipid Res. 1997, 35, 387-408.

20. Rontani, J.-F.; Beker, B.; Volkman, J. K. Long-chain alkenones and related compounds in the benthic haptophyte Chrysotila lamellosa Anand HAP 17. Phytochemistry 2004, 65, 117-126.

21. Farrimond, P.; Eglinton, G.; Brassell, S. C. Alkenones in cretaceous black shales, Blake-Bahama Basin, western North Atlantic. Org. Geochem. 1986, 10, 897-903.

22. Villanueva, J.; Flores, J. A.; Grimalt, J .O. A detailed comparison of the $\mathrm{Uk}^{\prime} 37$ and coccolith records over the past $290 \mathrm{k}$ years: Implications to the alkenone paleotemperature method. Org. Geochem. 2002, 33, 897-905

23. Rechka, J. A.; Maxwell, J. R. Characterization of temperature indicators in sediments and organisms. Org. Geochem. 1988, 13, 727-734.

24. Marlowe, I. T.; Brassell, S. C.; Eglinton, G.; Green, J. C. Long-chain alkenones and alkyl alkenoates and the fossil coccolith record of marine sediments. Chem. Geol. 1990, 88, 349-375.

25. Rieley, G.; Teece, M.; Peakman, T. M.; Raven, A. M.; Greene, K. J.; Clarke, T. P.; Murray, M.; Leftley, J. W.; Campbell, C. N.; Harris, R. P.; Parkes, R. J.; Maxwell, J. R. Long-chain alkenes of the haptophytes Isochrysis galbana and Emiliania huxleyi. Lipids 1998, 33, 617-625. 